\title{
FIBRINOLYTIC AND ANTIFIBRINOLYTIC ACTIVITY IN PREGNANCY
}

\author{
BY \\ S. S. NAIDOO, M. HATHORN, AND T. GILLMAN \\ From the C.S.I.R. Group for the Study of Growth and Ageing, Department of Physiology, Faculty of \\ Medicine, University of Natal; Durban, South Africa
}

(RECEIVED FOR PUBLICATION NOVEMBER 24, 1959)

Fibrinolytic activity and serum antifibrinolysin were estimated in normal pregnant women, during and after labour.

The decreased fibrinolytic activity found during labour returned to non-pregnant levels within 24 hours of delivery. During the same period, the serum antifibrinolysin was rapidly diminished.

It is suggested that the post-partum increase in fibrinolytic activity to non-pregnant levels is due to alterations in the fibrinolytic system itself, as well as to changes in circulating antifibrinolysin.

In a previous communication alterations in fibrinolytic activity during pregnancy were reported (Gillman, Naidoo, and Hathorn, 1959). It was shown that, within 13 to 15 weeks of the onset of pregnancy, fibrinolytic activity, as measured by euglobulin lysis time, was greatly reduced and remained so until the second stage of labour. Within 24 hours of delivery, there was a rapid increase in fibrinolytic activity, control levels being attained within 24 hours. These findings, using another method and in another racial group, were in agreement with the findings of Biezenski and Moore (1958).

However, the mechanism underlying these changes remains obscure. Whether the alteration in fibrinolytic activity during pregnancy is a function of fibrinolysin and/or precursors, antilysins, fibrin substrate, or a combination of these factors, is not known. To this end, serum antifibrinolytic activity was determined in nine pregnant African women, both during and after labour.

\section{Materials and Methods}

Pregnant African women in the first and second stage of labour were selected from the labour wards of the King Edward VIII Hospital. They were all medically healthy and obstetrically normal. In each of the women, determinations were made during labour and nine to 24 hours after parturition.

Collection of Blood.-The subjects were not under basal conditions. All blood samples were collected between 9 and 10 a.m. through a wide-bore needle inserted by clean venipuncture into the antecubital vein. The first few drops were discarded and $5 \mathrm{ml}$. of the freely flowing blood was collected in clean $10 \times 70 \mathrm{~mm}$. tubes containing $0.5 \mathrm{ml}$. of a $3.8 \%$ sodium citrate solution. The tubes were immediately placed in melting ice and transported to the laboratory.

Fibrinolysis.-Fibrinolysis was estimated within one hour of collecting blood by estimating euglobulin lysis time according to the method described by Von Kaulla and Schultz (1958). In essence this technique involves the isoelectric precipitation of euglobulin from citrated plasma, clotting with thrombin, and incubation at $37^{\circ} \mathrm{C}$. The euglobulin lysis time is taken as the interval between the adding of thrombin and the complete dissolution of the clot.

Antifibrinolytic Activity. $\rightarrow$ This was estimated according to the method of Guest, Ware, and Seegers (1947). Serum was obtained by adding a drop of thrombin to citrated plasma and whipping out fibrin with a glass rod.

\section{Results}

It will be seen from Table I that, despite wide variation in age and parity, the euglobulin lysis time decreased in all nine patients to a median of 165 minutes which approximates to the normal non-pregnant level previously found by us (Gillman et al., 1959). This decrease in euglobulin lysis time in all nine patients was statistically significant, and could only be expected by chance in less than one in a hundred patients $(P=0.01)$.

There was a decrease in antifibrinolytic activity in eight of these patients, and no change in the remaining patient. This, likewise, was statistically significant $(\mathrm{P}=0.01)$. 
TABLE I

EUGLOBULIN LYSIS TIMES IN NINE PATIENTS

\begin{tabular}{|c|c|c|c|c|c|c|c|c|}
\hline \multirow[b]{2}{*}{$\begin{array}{l}\text { Case } \\
\text { No. }\end{array}$} & \multirow[b]{2}{*}{ Age } & \multirow[b]{2}{*}{ Parity } & \multicolumn{3}{|c|}{ Before Delivery } & \multicolumn{3}{|c|}{ After Delivery } \\
\hline & & & Hours & $\begin{array}{l}\text { E.L.T.T. } \\
\text { (min.) }\end{array}$ & $\begin{array}{c}\text { Anti- } \\
\text { lysin } \\
\text { (units/ } \\
\text { ml.) }\end{array}$ & Hours & $\begin{array}{l}\text { E.L.T. } \\
\text { (min.) }\end{array}$ & $\begin{array}{c}\text { Anti- } \\
\text { lysin } \\
\text { (units/ } \\
\text { ml.) }\end{array}$ \\
\hline $\begin{array}{l}1 \\
2 \\
3 \\
4 \\
5 \\
6 \\
7 \\
8 \\
9^{*}\end{array}$ & $\begin{array}{l}19 \\
18 \\
30 \\
25 \\
32 \\
19 \\
28 \\
19 \\
28\end{array}$ & $\begin{array}{l}0 \\
1 \\
3 \\
3 \\
0 \\
1 \\
3 \\
0 \\
4\end{array}$ & $\begin{array}{r}3 \\
1 \\
1 \\
1 \\
5 \\
5 \\
13 \\
3 \\
1 \\
13\end{array}$ & $\begin{array}{l}360+ \\
360+ \\
300 \\
360+ \\
180 \\
242 \\
360+ \\
360+ \\
360+\end{array}$ & $\begin{array}{l}437 \\
537 \\
655 \\
600 \\
650 \\
715 \\
915 \\
500 \\
550\end{array}$ & $\begin{array}{l}21 \\
23 \\
23 \\
23 \\
20 \\
11 \\
21 \\
23 \\
11\end{array}$ & $\begin{array}{l}210 \\
125 \\
130 \\
130 \\
165 \\
165 \\
250 \\
225 \\
100\end{array}$ & $\begin{array}{l}200 \\
175 \\
375 \\
250 \\
525 \\
525 \\
575 \\
500 \\
535\end{array}$ \\
\hline
\end{tabular}

* Twin delivery.

\section{Discussion}

Biezenski and Moore (1958) found that the proportion of pregnant women showing complete lysis of clots rose abruptly after delivery, indicating an increase in overall fibrinolytic activity. This finding was substantiated by Gillman et al. (1959), who demonstrated a marked decrease in euglobulin lysis time within the first 24 hours after birth.

Changes in overall fibrinolytic activity may result from alterations in fibrinolysin and/or its precursors, antilysins, fibrin substrate, or a combination of these factors. Plasma fibrinogen concentrations show no significant changes immediately following delivery (Gram, 1921 ; Plass and Matthew, 1926; Gillman et al., 1959) and attention must thus be directed to the other components listed above.

In the present study, we have shown that, in addition to decreased euglobulin lysis time, there is also a significant decrease in antifibrinolysin following delivery. The question naturally arises as to whether this change in euglobulin lysis time may be partly or wholly due to the decrease noted in plasma antifibrinolysin.

Several reports in the literature indicate that antifibrinolysin is present mainly in the pseudoglobulin fraction of plasma proteins. Thus Macfarlane and Pilling (1946) could detect no plasmin-inhibiting activity in euglobulin precipitated at $p \mathrm{H} 5.5$ and low ionic strength, whereas large amounts were present in the supernatant containing the pseudoglobulins. Milstone (1941), too, could detect inhibiting activity only in the pseudoglobulin fraction. More recently, Kowalski, Kopeć, and Niewiarowski (1959) found only traces of antiplasmin in euglobulin precipitates.

Thus in the euglobulin lysis time method of estimating fibrinolytic activity, most of the antifibrinolysin in the plasma is presumably excluded from the euglobulin precipitate. The euglobulin lysis time is thus probably an expression of total fibrinolytic activity without interference from antifibrinolysin, even though large amounts of the latter may be present in the native plasma from which the euglobulins are precipitated. Alterations in the lysis times of such a system will thus be due mainly to changes in one or more components of the fibrinolytic system itself.

Guest (1954) found an increase in antifibrinolysin during pregnancy. Our present findings confirm and extend this observation by showing that this excess antifibrinolysin is rapidly diminished within 24 hours of delivery. Our results thus disclose at least two contributory factors that may account for changes in fibrinolytic activity after delivery. These are, first, an increase in fibrinolysin (or precursors) and, secondly, a decrease in antifibrinolysin.

We wish to thank the Nuffield Foundation, the Parke, Davis Company, and the Council for Scientific and Industrial Research for financial assistance, Dr. S. Disler, Superintendent of King Edward VIII Hospital, and Professor Derk Crichton for access to his cases.

We also wish to thank Mr. R. Paul of Petersens (S.A.) Ltd. for Armour's bovine fibrinogen, and the Parke, Davis Company for thrombin topical and fibrinolysin.

\section{REFERENCES}

Biezenski, J. J., and Moore, H. C. (1958). J. clin. Path., 11, 306. Gillman, T. Naidoo, S. S., and Hathorn, M. (1959). Lancet, 2, 70. Gram, H. C. (1921), Arch. intern. Med., 28,312

Gram, H. C..(1921). Arch. intern. Med., 28, 312.

Guest, M. M. (1954). J. clin. Invest., 33, (1947). Amer. J. Physiol., 150,661 .

Kowalski, E., Kopec, M., and Niewiarowski, S. (1959). J. clin. Path., 12, 215.

Macfarlane, R. G., and Pilling, J. (1946). Lancet, 2, 562.

Milstone, H. (1941). J. Immunol., 42, 109.

Plass, E. D., and Matthew, C. W. (1926). Amer. J. Obstet. Gynec., 12, 346 .

Von Kaulla, K. W., and Schultz, R. L. (1958). Amer. J. clin. Path., 29, 104 . 